Article

\title{
Changes in Cold Surge Occurrence over East Asia in the Future: Role of Thermal Structure
}

\author{
Jin-Woo Heo ${ }^{1}$, Chang-Hoi Ho ${ }^{1, *}$, Tae-Won Park ${ }^{2}$, Woosuk Choi ${ }^{1}$, Jee-Hoon Jeong ${ }^{3}$ and \\ Jinwon Kim ${ }^{4}$ \\ 1 School of Earth and Environmental Sciences, Seoul National University, Seoul 08826, Korea; \\ ion@snu.ac.kr (J.-W.H.); choiwoossa@gmail.com (W.C.) \\ 2 Department of Earth Science Education, Chonnam National University, Gwangju 61186, Korea; \\ park2760@gmail.com \\ 3 Department of Oceanography, Chonnam National University, Gwangju 61186, Korea; jjeehoon@gmail.com \\ 4 Climate Research Division, National Institute of Meteorological Research, Jeju 63568, Korea; \\ jkim@atmos.ucla.edu \\ * Correspondence: hoch@cpl.snu.ac.kr
}

Received: 23 April 2018; Accepted: 7 June 2018; Published: 10 June 2018

\begin{abstract}
The occurrence of wintertime cold surges (CSs) over East Asia is largely controlled by the surface air temperature (SAT) distribution at high latitudes and thermal advection in the lower troposphere. The thermodynamic background state over northeastern Asia is associated with the strength of the East Asian winter monsoon and the variation of Arctic Oscillation. This study assesses the importance of the SAT structure with thermal advection in determining the frequency of CS occurrences over East Asia through the analysis of nine atmosphere-ocean coupled global climate models participating in the Coupled Model Intercomparison Project Phase 5. The historical simulations can reproduce the observed typical characteristics of CS development. On the basis of this model performance, ensemble-averaged future simulations under the representative concentration pathway 8.5 project a reduction in CS frequency by $1.1 \mathrm{yr}^{-1}$ in the late 21st century (2065-2095) compared to the present-day period (1975-2005). The major reason for less frequent CSs in the future is the weakened cold advection, caused by notable SAT warming over the northern part of East Asia. These results suggest that changes in the meridional SAT structure and the associated changes in thermal advection would play a more substantial role than local warming in determining future changes in the frequency of CS occurrences over East Asia.
\end{abstract}

Keywords: cold surge; thermal advection; East Asian winter monsoon; Arctic Oscillation; meridional surface air temperature; Coupled Model Intercomparison Project phase 5

\section{Introduction}

Cold surges (CSs), characterized by a steep temperature drop within one or two days, are energetic systems associated with the East Asian winter monsoon (EAWM). Northerly winds bring cold air from high-latitude regions into East Asia, leading to an abrupt drop in local temperature. These winds often penetrate even further south, altering convective activity off the South China Sea and adjacent regions [1,2]. Strong CSs are often accompanied by severe weather conditions such as freezing precipitation and heavy snowfall along coastal regions in East Asia (when sufficient humidity is available) [3-5]. Consequently, the CSs, which occur about ten times per winter [6], have severe impacts on socio-economical human activities in East Asian countries.

The semi-permanent Siberian High develops in association with radiative cooling at the surface and large-scale subsidence motions during boreal winter $[7,8]$. On the eastern flank of the Siberian 
High, climatological northerlies exist with a tight meridional temperature gradient near the surface. The interaction between lower- and upper-level atmospheric perturbations known as the vertical westward-tilted structure is the primary mechanism leading to amplification of the Siberian High on intraseasonal time scales. Perturbations of atmospheric circulation often provide strong cold advection by bringing pre-existing colder air from northern Eurasia to extend the Siberian High. Along with the development of the Siberian High, the mean state of thermal advection by anomalous winds plays a critical role in cold air outbreaks into East Asia $[9,10]$. The intensity of cold advection is mainly determined by the meridional distribution of mean state temperature. Changes in the meridional distribution of mean state temperature strongly affect both the Siberian High and the occurrence of CSs.

Previous studies have shown that the frequency of CSs is remotely influenced by large-scale climate variabilities such as the Arctic Oscillation (AO) [11], Madden-Julian Oscillation (MJO) [12], and El Niño-Southern Oscillation (ENSO). During the negative phase of the AO, the large-scale circulation brings cold air to East Asia from northern Eurasia, creating an environment that favors strong cold advection [13,14]. Jeong and Ho [13] and Woo et al. [15] reported that more frequent, stronger, and longer-lasting CSs occur in decades of a negative phase of $\mathrm{AO}$. When the MJO convective center is located in the Indian Ocean (i.e., MJO phase 2-3), the large-scale extratropical circulation is changed in a way that can amplify CSs [16]. The suppression of convective activity in the maritime continent associated with the weak EAWM in El Niño years provides unfavorable conditions for CS occurrences [6,17]. These large-scale climate variabilities affect CS occurrence by changing the mean state temperature distribution. In addition, recent studies have reported that sea ice loss in the Barents-Kara sea can modulate atmospheric circulation in Eurasia by direct Rossby wave propagation [18-20] or by indirect modulation via stratospheric circulation [21]. These remote modulations influence CS frequency through their effects on the cold advection associated with the meridional temperature gradient.

While global surface warming inevitably reduces the number of cold days [22], its effect on the frequency of cold extremes at regional scales remains controversial [23,24]. Under global warming, a huge amount of sea ice is anticipated to melt, which would lead to widespread effects at mid-latitudes [18,25-27]. For example, Kug et al. [28] found that the Arctic warming associated with reduced sea ice could lead to cold extremes in the extratropics by inducing upper tropospheric wave trains. Arctic amplification, a larger warming in the lower troposphere over Arctic regions than in other regions, may play an important role in the occurrence of CSs by affecting mid-latitude synoptic temperature variability. Francis and Vavrus [25] suggested that Arctic amplification reduces the meridional temperature gradient, resulting in a weaker jet stream. Under weaker jet conditions, mid-latitude synoptic disturbances tend to be more active, and more blocking events occur, which favors both warm and cold extremes [29]. At the same time, it is possible that the weaker meridional temperature gradient resulting from Arctic warming could reduce temperature variability locally through a weakening of cold advection from the north [30].

Previous studies have pointed out the local mean surface air temperature (SAT) warming could not be the possible reason for changes of CS occurrences over East Asia in future climate [23]. Here, we explore what is an essential factor for changes of CS occurrences over East Asia in various time scale on the basis of both observation and climate-projected simulation of models participated in the Intergovernmental Panel on Climate Change, Fifth Assessment Report. This study provides an insight into how the future global warming influences CSs occurrences over East Asia.

This paper is organized as follows. Section 2 describes the data used in this study, the definition of CSs adopted here, and the temperature advection analysis. In Section 3, we compare the observed vertical and horizontal structure of CSs to the structure simulated by atmosphere-ocean coupled global climate models (CGCMs), and then examine how CS frequency is expected to change in the future and the mechanisms responsible for those changes. Section 4 provides discussion and summary. 


\section{Data and Methods}

\subsection{Data}

To identify CS occurrences in the observational record, the daily mean SAT and mean sea level pressure (SLP) are obtained from the European Center for Medium-Range Weather Forecasts Re-Analysis Interim [31], which has a horizontal resolution of $1.5^{\circ} \times 1.5^{\circ}$. Daily temperature, geopotential height, and wind at 250 and $850 \mathrm{hPa}$ are used to identify CS structures. The monthly mean AO index is obtained from the National Oceanic and Atmospheric Administration Climate Prediction Center. We analyze 388 cold surges detected in cold seasons (November through March) of 1979/80-2016/17.

We use the results from nine CGCMs belonging to Coupled Model Intercomparison Project Phase 5 (CMIP5): ACCESS1-3, BNU-ESM, CanESM2, CMCC-CESM, CMCC-CMS, GFDL-ESM2G, MPI-ESM-LR, MPI-ESM-MR, NorESM1-M. Brief model descriptions are given in Table 1. These nine CGCMs are selected because they successfully reproduce the observed climatological center of the Siberian High and provide the variables required to analyze the structure and characteristics of CSs (see Figure S1 for details). We use model simulation data from the historical run and the $8.5 \mathrm{~W}$ $\mathrm{m}^{-2}$ representative concentration pathway (RCP8.5) emission scenario [32]. The historical run is an experiment with all forcing in the 20th century. The RCP8.5 emission scenario is the pathway with the highest greenhouse gas emissions. We select thirty-year periods from both the historical and the RCP8.5 runs: 1975-2005 and 2065-2095, respectively. All CMIP5 data are re-gridded to $3.75^{\circ} \times 3.75^{\circ}$ (the coarsest resolution among the nine CGCMs) for consistency. The monthly AO index is calculated in each CGCM by projecting the monthly SLP anomalies poleward of $20^{\circ} \mathrm{N}$ onto the first leading mode of their empirical orthogonal functions.

Table 1. Details of CMIP5 models used in this study.

\begin{tabular}{ccc}
\hline Model & Institution & Atmospheric Resolution \\
\hline ACCESS1-3 & Commonwealth Scientific and Organization, Bureau of Meteorology & 192,145 N96 \\
BNU-ESM & Beijing Normal University & $\mathrm{T} 42$ \\
Can-ESM2 & Canadian Center for Climate Modeling and Analysis & $\mathrm{T} 63$ \\
CMCC-CESM & Centro Euro-Mediterraneo per I Cambiamenti Climatici & $\mathrm{T} 31$ \\
CMCC-CMS & Centro Euro-Mediterraneo per I Cambiamenti Climatici & $\mathrm{T} 63$ \\
GFDL-ESM2G & NOAA Geophysical Fluid Dynamics Laboratory & $2.5^{\circ} \times 2^{\circ}$ \\
MPI-ESM-LR & Max Planck Institute for Meteorology & $\mathrm{T} 63$ \\
MPI-ESM-MR & Max Planck Institute for Meteorology & $\mathrm{T} 63$ \\
NorESM1-M & Norwegian Climate Centre & $1.9^{\circ} \times 2.5^{\circ}$ \\
\hline
\end{tabular}

\subsection{Definition of CS Occurrences}

The synoptic criteria adopted in this study to detect wintertime CSs over East Asia are similar to those used in previous studies $[15,16,33,34]$. CSs are defined as follows. First, days associated with an expansion of the Siberian High are identified when the daily SLP exceeds $1030 \mathrm{hPa}$ in an anticyclone center. An anticyclone center is defined as the grid point where the SLP is larger than in the eight surrounding grid points. The domain of the Siberian High is the rectangular region defined by $35^{\circ} \mathrm{N}-55^{\circ} \mathrm{N}$ and $90^{\circ} \mathrm{E}-115^{\circ} \mathrm{E}$ (Figure 1a). Second, the SAT drop should exceed 1.5 standard deviations $(\sigma)$ of the daily winter SAT anomaly within one or two days over northeastern China or Korea (domains defined by $40^{\circ} \mathrm{N}-45^{\circ} \mathrm{N}, 120^{\circ} \mathrm{E}-125^{\circ} \mathrm{E}$ and $35^{\circ} \mathrm{N}-40^{\circ} \mathrm{N}, 125^{\circ} \mathrm{E}-130^{\circ} \mathrm{E}$, respectively; Figure 1a). These two 5-degree domains can represent East Asia considering that the amplification and expansion of Siberian High have influenced not only SAT domains, but also other East Asian regions. Third, the daily SAT must be below the climatological mean for that day. This condition excludes relatively warm CSs (i.e., the temperature drops abruptly but remains warmer than the climatological average). To separate consecutive CSs, the termination of the CS is defined the first day when the daily SAT anomaly rises above $-0.5 \sigma$ after the CS occurrence. For explaining detection of CS occurrences, 
the time series of SAT over Korea and mean SLP averaged over Siberian High domain for the period of January in 2009 are shown in Figure 1b,c, respectively. In this period, two CS occurrences are identified, on 10 and 23 January 2009 (Figure 1b). Before the CS occurrence dates, there are expansions of Siberian High (Figure 1c), which would satisfy the first criterion, daily SLP exceeding $1030 \mathrm{hPa}$. Second, the large SAT drops are identified in CS occurrence dates in which SAT anomaly is below daily climatology as third criterion. Termination dates are identified before recovering climatology of SAT, which separates two CSs. In addition, the reference date of all CS composites is the CS occurrence date. In the CMIP5 model results, we calculate the present-day and future SAT anomaly as deviations from the daily climatology for 1975-2005 and 2065-2095, respectively. To allow comparison with the 30-year future run, $\sigma$ is calculated over only 30 years of the historical run (1975-2005). Thus, we use the same SAT drop criteria to define CSs in the historical and future runs.
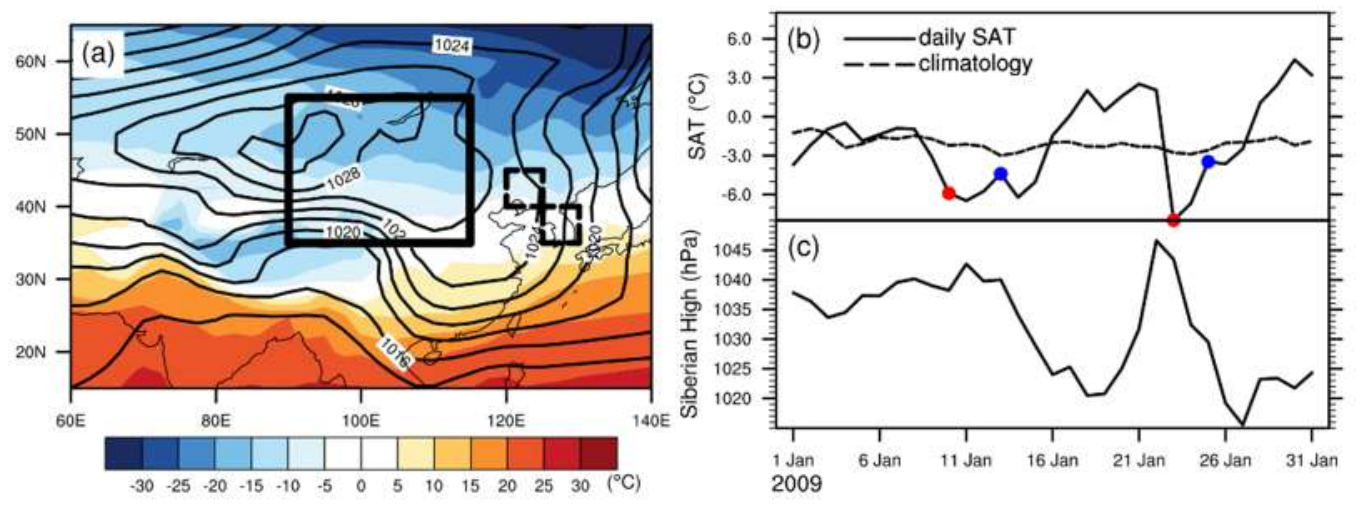

Figure 1. (a) The SAT domains of East Asia (two dashed boxes; $35^{\circ} \mathrm{N}-40^{\circ} \mathrm{N}, 125^{\circ} \mathrm{E}-130^{\circ} \mathrm{E}$ and $40^{\circ}$ $\mathrm{N}-45^{\circ} \mathrm{N}, 120^{\circ} \mathrm{E}-125^{\circ} \mathrm{E}$ ) and the domain of the Siberian High (solid box; $35^{\circ} \mathrm{N}-55^{\circ} \mathrm{N}, 90^{\circ} \mathrm{E}-115^{\circ} \mathrm{E}$ ) used to define cold surges. The climatology of observed mean SLP (contour interval of $2 \mathrm{hPa}$ ) and SAT (shading) during the winter season (November to March). (b) Times series of daily SAT (solid line) and its climatology (dash line) averaged over $35^{\circ} \mathrm{N}-40^{\circ} \mathrm{N}, 125^{\circ} \mathrm{E}-130^{\circ} \mathrm{E}$ during January in 2009. Red (blue) dots indicate the occurrence (termination) date of CSs. (c) Time series of daily SLP averaged over the domain of Siberian High during the same period mentioned in Figure $1 \mathrm{~b}$.

\subsection{Thermodynamic Interpretation}

We analyze thermal advection terms in the temperature tendency equation at $850 \mathrm{hPa}$ when CSs occur. We note that cold advection is essential for amplification of the Siberian High [9] and the occurrence of CSs. Assuming an isentropic surface, the anomalous temperature tendency at $850 \mathrm{hPa}$ is decomposed as follows:

$$
\frac{\partial T^{\prime}}{\partial t}=-V^{\prime} \cdot \nabla \bar{T}-\bar{V} \cdot \nabla T^{\prime}-V^{\prime} \nabla T^{\prime}+V A
$$

where $T$ is the temperature, $V$ is the horizontal wind vector, $V A$ is the vertical advection, and $\nabla$ is the horizontal gradient operator. Each variable is decomposed into the overbar and prime, which denote daily climatological mean and anomaly, respectively. In this study, we estimate the climatological temperature advection by the anomalous wind $\left(V^{\prime} \cdot \nabla \bar{T}\right)$, the anomalous temperature advection by the climatological wind $\left(\bar{V} \cdot \nabla T^{\prime}\right)$, and the anomalous temperature advection by the anomalous wind $\left(V^{\prime} \cdot \nabla T^{\prime}\right)$. We neglect the vertical advection $(V A)$ because its contribution is small.

\section{Results}

\subsection{Simulation of the CS Structure}

The general characteristic of CS structure is known for vertically westward tilted geopotential height and accompanies cold advection over East Asia resulting from the expansion of the Siberian 
High $[9,15,33]$. We compare the spatial patterns and vertical structures of observed CSs to those simulated in the CGCMs prior to investigating future changes in CSs and the contribution of thermal advection to those changes.

The geopotential height patterns at 250 and $850 \mathrm{hPa}$ are shown during the dates of CS occurrence in observation (Figure 2a). The upper-tropospheric ridge-trough-ridge geopotential height pattern stretches from the Ural Mountains $\left(50^{\circ} \mathrm{E}-90^{\circ} \mathrm{E}, 50^{\circ} \mathrm{N}-75^{\circ} \mathrm{N}\right)$ to the Korea-Japan region $\left(120^{\circ} \mathrm{E}-140^{\circ} \mathrm{E}\right.$, $30^{\circ} \mathrm{N}-45^{\circ} \mathrm{N}$ ). The ridge-trough-ridge is arranged in a northwest-southeast direction in the upper troposphere and the anticyclonic-cyclonic couplet stretches from eastern flank of the Siberian High to East Asia in the lower troposphere. These upper- and lower-tropospheric synoptic patterns proceed eastward and imply a westward-tilted vertical structure in which the lower-level circulation leads the upper-level circulation by about a quarter of a wavelength. The westward-tilted vertical structures in geopotential height associated with CSs in the ensemble mean and all nine CGCMs are similar to the observed structures [35]. However, the magnitude and location of the geopotential heights are slightly different in each model (Figure 2c-k). In ACCESS1-3, BNU-ESM, CanESM2, CMCC-CESM, and GFDL-ESM2G, the magnitude of the upper-level ridge over the Ural Mountains is underestimated (Figure 2c,f,h). The strong lower-level anticyclone over the Lake Baikal is simulated in CMCC-CMS, MPI-ESM-LR, and MPI-ESM-MR (Figure 2g,i,j). In BNU-ESM, the direction of the lower-level anticyclone-cyclone couplet is more northward than the observation (Figure 2d).
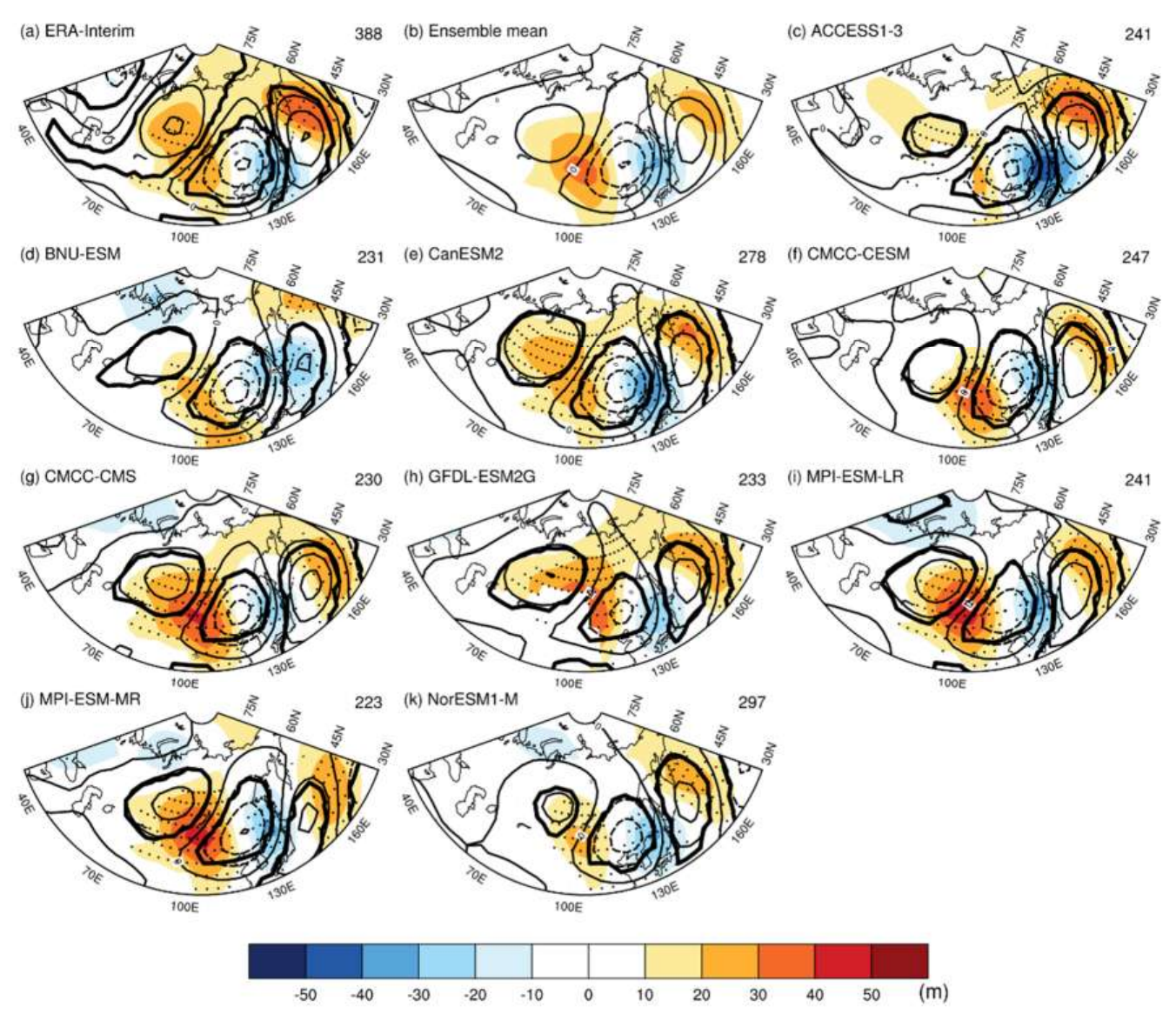

Figure 2. Composite of geopotential height anomalies at $250 \mathrm{hPa}$ (contour interval of $30 \mathrm{~m}$; values significant at the $99 \%$ confidence level are represented by thick lines) and at $850 \mathrm{hPa}$ (shading; values significant at the $99 \%$ confidence level are represented by black dots) for cold surge occurrence dates identified in the ERA-Interim data, the output of the nine CGCMs for the historical run, and the ensemble mean of the CGCMs for the historical run. The number of CS occurrences for composite are represented on the top-right of each panel. 
Figure 3 displays the spatial patterns of the SLP and SAT anomalies during CS occurrences in the reanalysis data and CGCM outputs. The positive SLP anomaly in the inner continent and the negative SLP anomaly in the western North Pacific are well shown (Figure 3a). The expansion of the positive SLP anomaly to East Asia is associated with intensification of the Siberian High (not shown). The anomalous northerly located between positive and negative SLP anomalies induces strong cold advection into East Asia across the climatological meridional SAT gradient. The magnitude and location of the SLP and SAT anomaly maxima in the ensemble mean results are in good agreement with those in the observations (Figure 3b). In the ACCESS1-3, the positive SLP anomalies are weaker than the negative SLP anomalies, in contrast to the observations and the results from the other CGCMs (Figure 3c). BNU-ESM, CanESM2, and GFDL-ESM2G simulate relatively wide and intense cold anomalies (Figure 3d,e,h). Overall, the historical simulations capture the westward tilt of the geopotential height patterns and cold SAT anomalies in eastern flank of positive SLP anomalies at $850 \mathrm{hPa}$, indicating that the CGCMs are able to simulate the general structure of CSs.

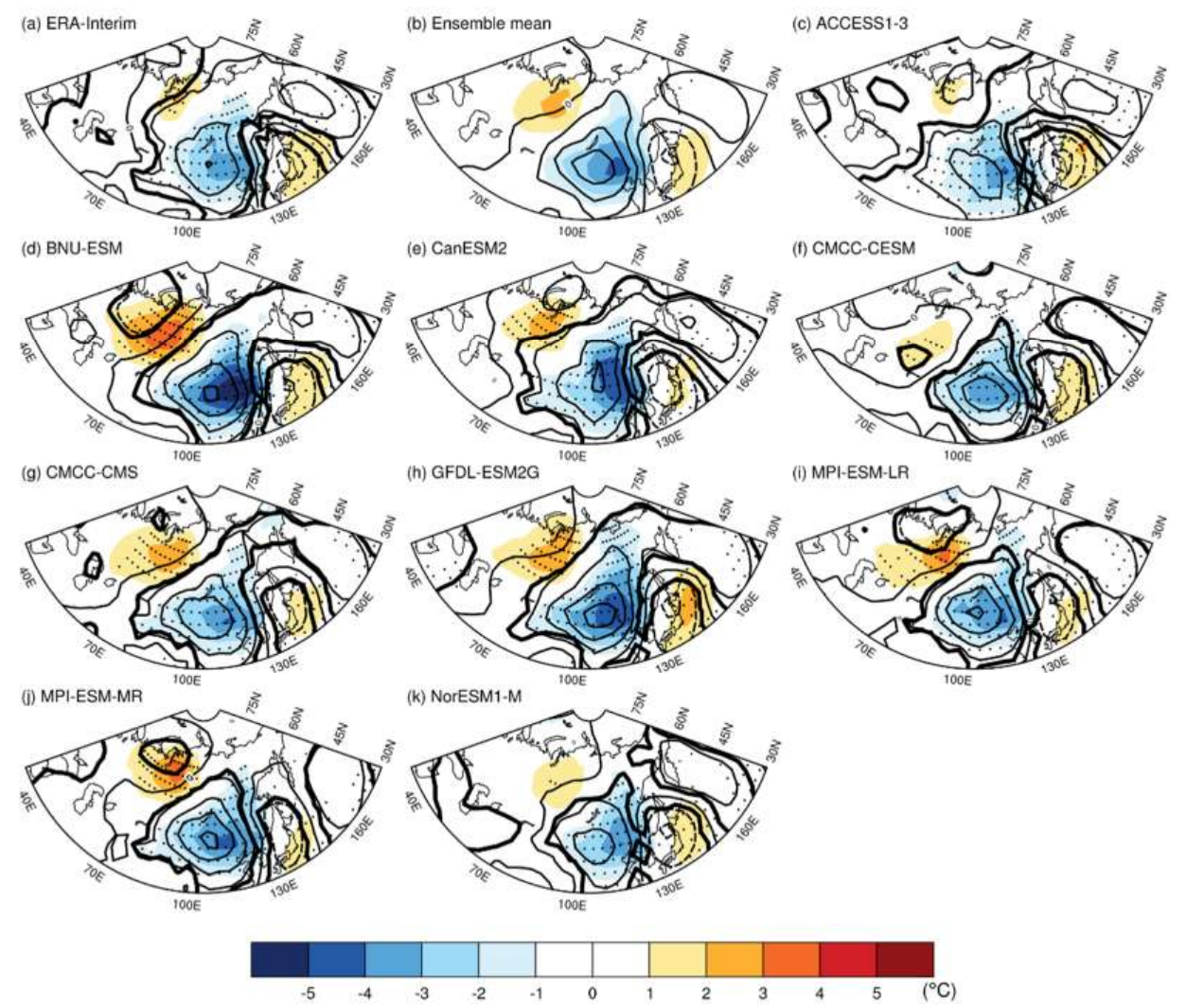

Figure 3. Composite of SLP anomalies (contour interval of $2 \mathrm{hPa}$; values significant at the $99 \%$ confidence level are represented by thick lines) and SAT anomalies (shading; values significant at the $99 \%$ confidence level are represented by black dots) for cold surge occurrence dates identified in the ERA-Interim data, the output of the nine CGCMs for the historical run, and the ensemble mean of the CGCMs for the historical run.

\subsection{Thermodynamic Environment in Association with CS Occurrence}

Takaya and Nakamura [36] suggested that a pre-existing cold anomaly over the northern part of the Siberian High is important to the intensification of the anticyclone that is necessary before a cold air outbreak can occur over East Asia. After the intensification of the Siberian High, low-level thermal advection plays a crucial role in the occurrence of CSs over East Asia. Thus, we examine the thermal advection terms at $850 \mathrm{hPa}$ during CS occurrences. We divide the temperature gradient and wind vector terms into a daily climatology term and an anomaly (deviation from the climatology) term to identify the effects of climatological thermal advection on CS occurrences. 


\subsubsection{Relative Importance of the Temperature Advection Terms}

Figure 4 shows the temperature anomaly (Figure $4 \mathrm{a}, \mathrm{e}$ ) and the temperature advection terms in dates of CS occurrences (Figure $4 \mathrm{~b}, \mathrm{~d}, \mathrm{f}, \mathrm{h}$ ). The temperature anomaly patterns show that the cold anomaly approaches East Asia, leading to large temperature drops (Figure 4a). The role of each temperature advection term is explored based on its spatial pattern and spatial correlation coefficient with temperature anomaly pattern. When the negative (positive) area is located over East Asia, this temperature advection term contributes cold (warm) advection over East Asia. The climatological temperature advection by anomalous wind pattern (Figure 4b) induces cold advection over East Asia. This advection contributes to sustain and amplify cold anomaly located over East Asia. Spatial correlation coefficient between temperature anomaly and the climatological temperature advection by anomalous wind is 0.67 , which means the advection generally amplify temperature anomaly pattern. Anomalous temperature advection by climatological wind induces cold (warm) advection on the eastern flank of cold (warm) anomaly (Figure 4c). It means climatological north-westerly in winter moves the cold and warm anomaly eastward which does not induce cold advection over East Asia. The anomalous temperature advection by anomalous wind induces slightly weak cold (warm) advection into the southern (northern) part of East Asia (Figure 4d). The cooling (warming) in mid-latitude (high-latitude) regions may imply meridional energy exchanges. Each temperature advection term in the ensemble mean shows a similar spatial pattern to the observations and their spatial correlation coefficients are also similar with the observations (Figure 4e,h). Therefore, the climatological temperature gradient plays a critical role for the intensity of the cold advection that eventually leads to the development of CSs by carrying cold air into East Asia. The temperature distribution in the lower troposphere would change CS occurrence through the variation of cold advection.
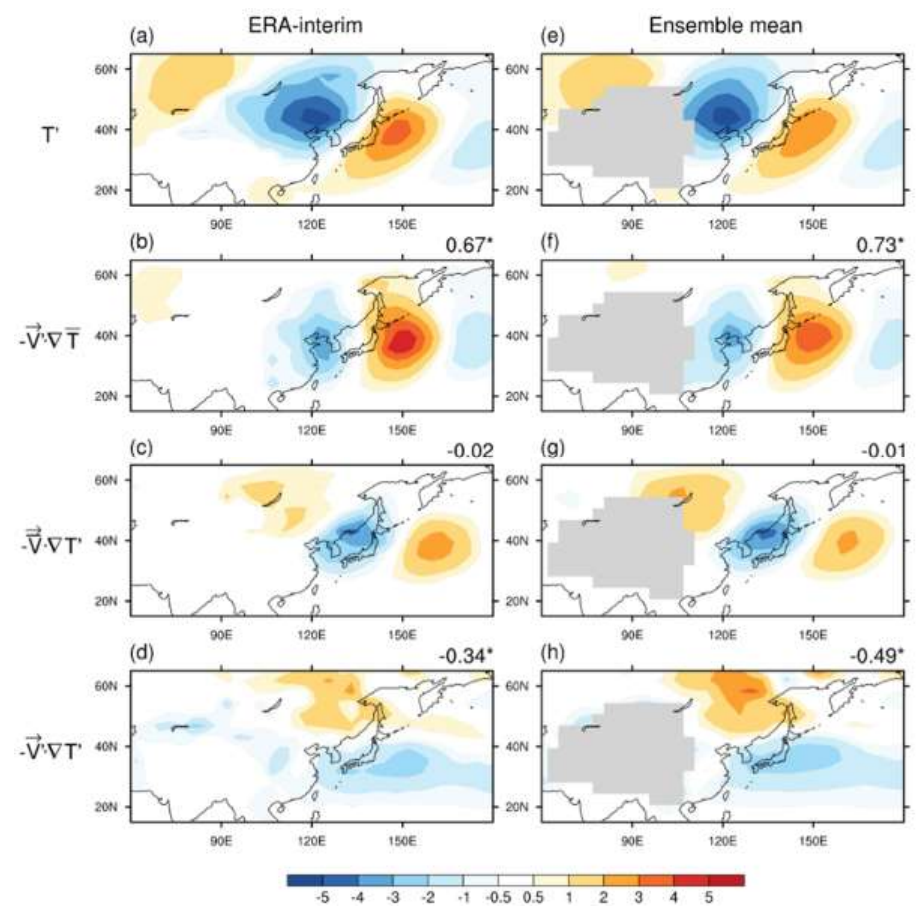

Figure 4. Composites for cold surge occurrence dates of the ERA-Interim (a) temperature anomalies $\left({ }^{\circ} \mathrm{C}\right),(\mathbf{b})$ advection of climatological temperature by anomalous wind $\left({ }^{\circ} \mathrm{C}\right.$ day $\left.^{-1}\right),(\mathbf{c})$ advection of anomalous temperature by climatological wind, and (d) advection of anomalous temperature by anomalous wind at $850 \mathrm{hPa}$. (e-h) are same as (a-d) but for the ensemble mean of the nine CGCMs in the historical run. The spatial correlation coefficients between each advection term and temperature anomalies are shown in the top-right of each panel (values significant at $99 \%$ confidence level are represented by black stars). 


\subsubsection{Importance of Meridional SAT Gradient and Local SAT Anomaly}

The importance of the meridional SAT gradient and the local SAT anomaly for CS occurrences is assessed by a sensitivity test in which the definition of a CS occurrence is varied. At mid-latitudes, the SAT drop is mainly caused by cold advection, and its intensity is related to the meridional SAT gradient. As described in Section 2, in this study, a CS occurrence is defined as an SAT drop of $1.5 \sigma$ coincident with a negative SAT anomaly. For the sensitivity test, we check how the frequency of CS occurrences changes as we vary the SAT drop criterion and the daily SAT anomaly criterion (Figure 5). We find that in both the observational data and the CGCMs, the change in the frequency of CS occurrences is more sensitive to changes in the SAT drop criterion than to changes in the anomaly criterion. Changing the daily SAT anomaly criterion can be interpreted as seasonal mean warming/cooling in wintertime. For example, if we change the daily SAT anomaly criterion for a $\mathrm{CS}$ to be below $-1{ }^{\circ} \mathrm{C}$, ideally, that can be regarded as the region experiencing $1{ }^{\circ} \mathrm{C}$ of warming in winter. Thus, the finding that the CS occurrence is less sensitive to change in the daily SAT anomaly criterion than to changes in the SAT drop criterion emphasizes that changes in cold advection would have greater effects on CS occurrence than local mean SAT warming in a future climate.
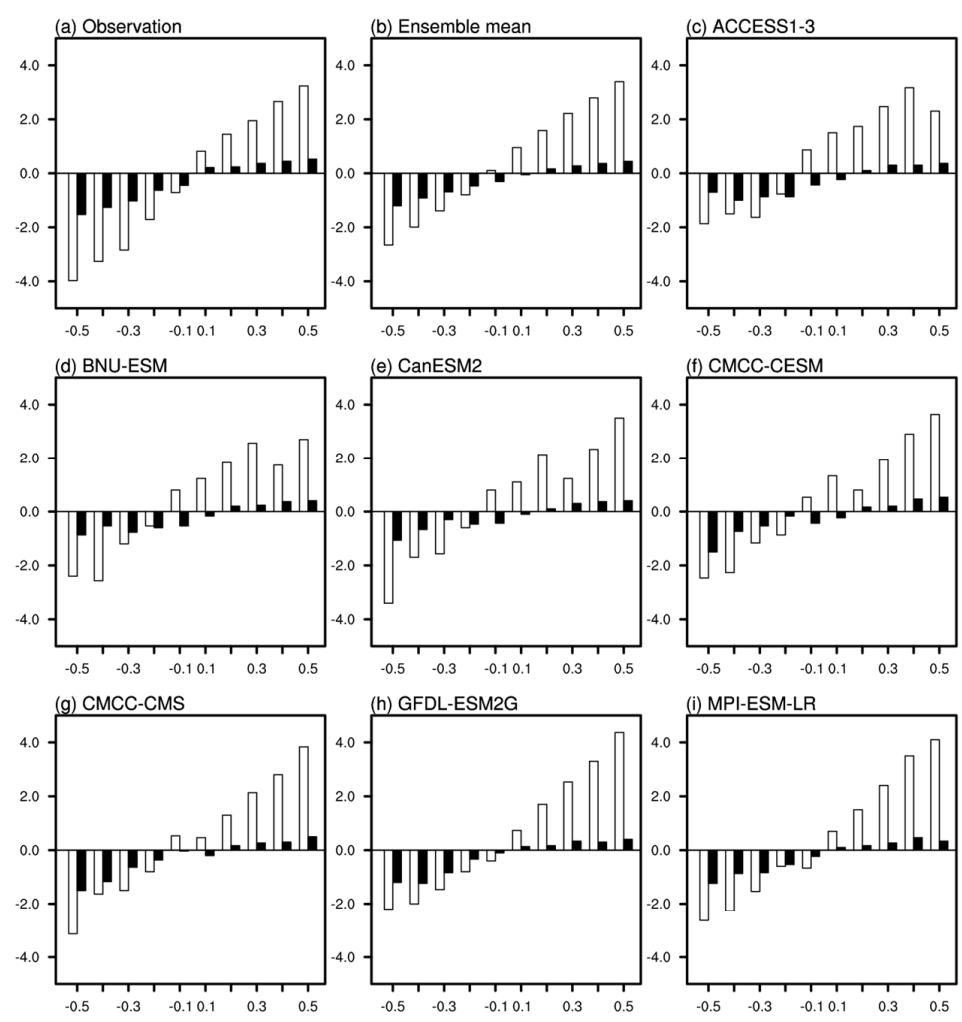

(h) GFDL-ESM2G

(i) MPI-ESM-LR
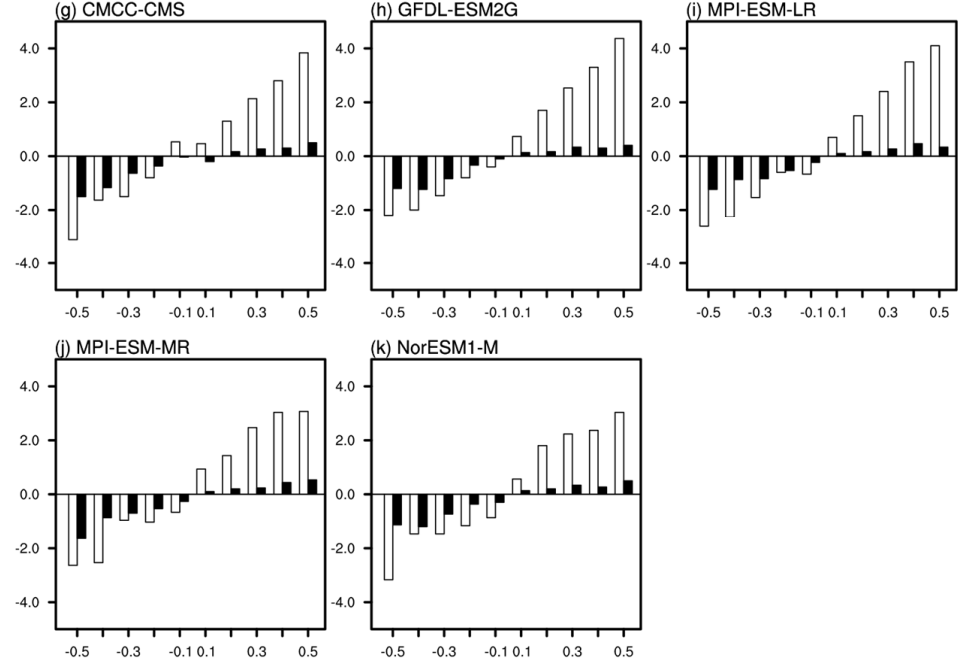

Figure 5. Changes in the frequency of cold surge occurrences $\left(\mathrm{yr}^{-1}\right)$ with changes in the criteria for the identification of cold surges (the temperature drop criterion is shown in the white bar and the temperature anomaly criterion is shown in the black bar). The horizontal axis is divided by the standard deviation of the winter daily SAT anomaly. 


\subsubsection{Influence of the SAT Gradient in Interannual Time Scale}

On the interannual time scale, the thermodynamic environment (i.e., mean state of SAT) affects the frequency of CSs. Figure 6 shows the spatial patterns of the interannual correlation coefficients between the mean number of CS occurrences over East Asia and the mean SAT in each winter for both the observations and the ensemble means of the historical and future CGCM runs. In the observations, negative and positive correlation coefficients are located over northern and southern regions, respectively (Figure 6a). The area of negative correlation coefficients spreads zonally from the northern regions of Mongolia to East Asia. If the northern surface air is cold and the meridional SAT gradient steepens, the conditions are favorable for CS genesis. While the regions with negative correlation coefficient are rather different in the historical run and the RCP8.5, both display negative correlation coefficients over the northern part of East Asia (Figure $6 b, c)$. In the historical run, the center of negative correlation coefficient is located over the northeastern regions of the analysis domain, while in the RCP8.5 run, the center is located over the northern regions. The difference in the location of the negative correlation coefficients may be due to the difference between blocking and wave-train CSs [33], which were not considered in this study and there are limitations to simulate the positive correlation coefficient over the southern regions in CGCMs. The meridional SAT gradient over eastern Eurasia has a crucial role for the frequency of CSs in interannual time scale, which could support the importance of thermal structure for predicting the number of CS occurrences in future climate.

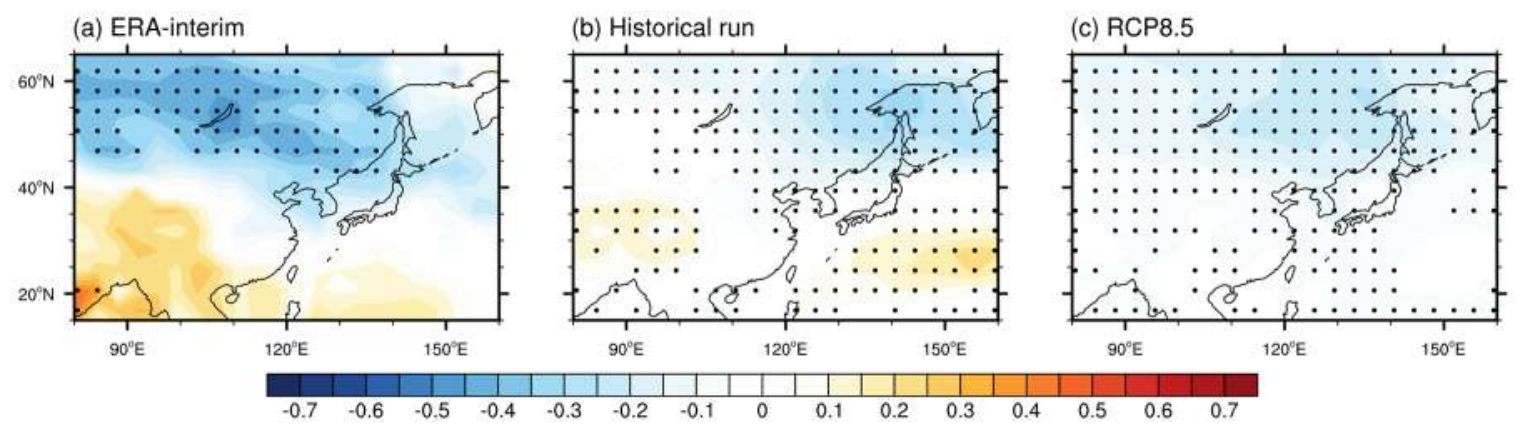

Figure 6. The interannual correlation coefficient between the occurrence of cold surges and the boreal winter SAT for (a) 1979-2016 in ERA-Interim (values significant at the 95\% confidence level are represented by black dots), (b) 1975-2005 in the historical run, and (c) 2065-2095 in ensemble mean of nine CGCMs based on RCP8.5 scenario. Regions with same sign in at least 6 CGCMs are represented by black dots.

\subsubsection{Decadal Variability of CS Occurrence}

The importance of cold advection associated with SAT structure to CS occurrence can also be seen on decadal time scales. We divide the observational analysis period of 38 years into three periods: 1979-1987, 1988-1994, and 1995-2016 (Figure 7). The number of CS occurrences in 1979-1987 and 1995-2016 are $10.8 \mathrm{yr}^{-1}$ and $10.5 \mathrm{yr}^{-1}$, respectively. However, fewer CSs occur $\left(8.8 \mathrm{yr}^{-1}\right)$ in 1988-1994. During the period of 1988-1994, the SAT warming over Northern Eurasia decreases the meridional SAT gradient, especially since the center of the warming occurs in the northern part of the Siberian High (Figure 7a). The reduced meridional SAT gradient from the center of Siberian High to East Asia would lead to relatively warmer air by northerly in-weather systems in the region, providing unfavorable conditions for CS occurrence. The decadal changes in CS frequency described in Figure $7 \mathrm{~b}$ are consistent with previous studies [15,37]. In sum, CS occurrence is closely associated with low-level thermodynamic environments, especially the meridional SAT gradient over East Asia on decadal time scale. 
(a)

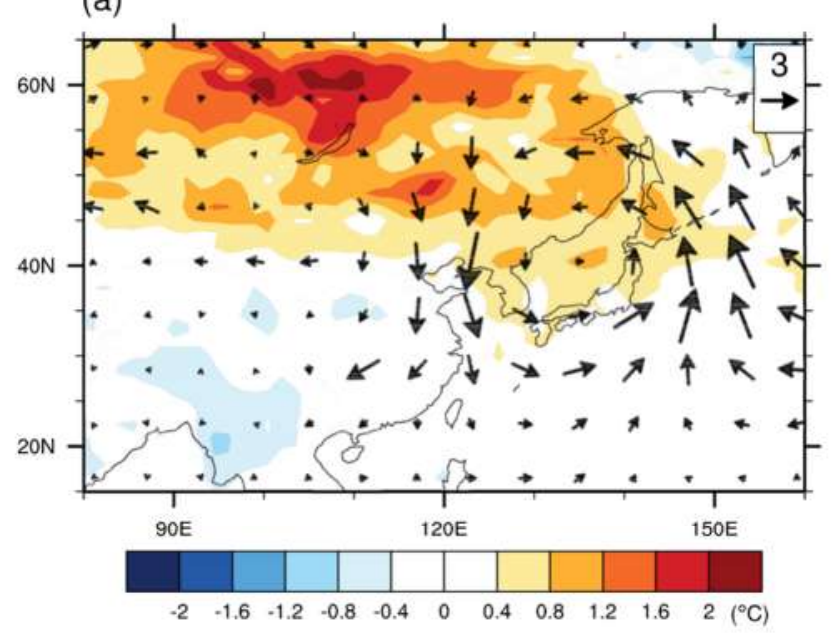

(b)

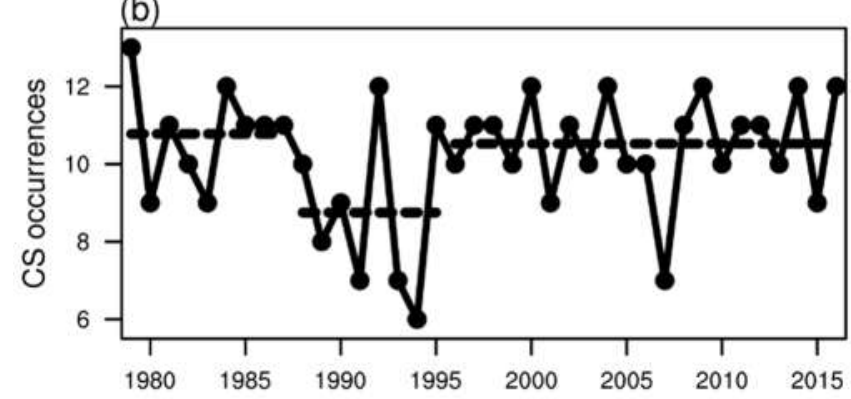

Figure 7. (a) SAT anomalies $\left({ }^{\circ} \mathrm{C}\right)$ during 1988-1994 from climatology in winter season and composite of daily wind anomalies at $850 \mathrm{hPa}$ for cold surge occurrence dates, (b) time series of the number of winter cold surge occurrences. The dashed lines show the mean number of cold surge occurrences during 1979-1987, 1988-1994, and 1995-2016.

\subsection{Projection of Future CS Occurrence Frequency under RCP8.5}

We compare the number of CS occurrences in the historical run (1975-2005) and future climate (2065-2095) (Figure 8). The number of CS occurrences per winter is $10.2 \mathrm{yr}^{-1}$ in the observational record and $8.2 \mathrm{yr}^{-1}$ in the ensemble mean for the historical (1975-2005) run. All nine CGCMs underestimate CS numbers compared to the observations, which may be caused by coarse resolution of CGCMs and different characteristics of SAT (see Table S1 for details) [23]. The CGCMs also project a decrease in CS occurrences in the future. Four CGCMs in particular (ACCESS1-3, CanESM2, MPI-ESM-LR, and NorESM1-M) predict significant decreases in the number of CS occurrences. In the ensemble mean, the frequency of CS occurrences decreases from $8.2 \mathrm{yr}^{-1}$ to $7.1 \mathrm{yr}^{-1}$ under global warming. The results of our sensitivity tests suggest that the weakened meridional SAT gradient in the future may be responsible for the decrease in CSs via weakening of cold advection.

The climatological SAT pattern in the historical run shows a typical winter structure in which high-latitude regions are colder than low latitude regions. While warming is clearly seen over the whole Eurasian continent in the future climate (Figure 9), the warming at high latitudes is more pronounced, particularly over eastern Eurasia continent. In the ensemble mean of the future, the zonal mean meridional SAT gradient along $80^{\circ} \mathrm{E}$ to $160^{\circ} \mathrm{E}$ is expected to decrease by about $1.5^{\circ} \mathrm{C}$ per 10 degrees of latitude (Figure 9a). All the CGCMs project similar decreases in the zonal mean meridional SAT gradient. These changes in the SAT distribution are clearly seen in most regions except for high altitude regions and the Sea of Okhotsk. The reduced meridional SAT gradient leads to relatively warmer advection. The warmer advection is unfavorable to CS development, leading to the projected decreases in CS frequency in the future climate. 


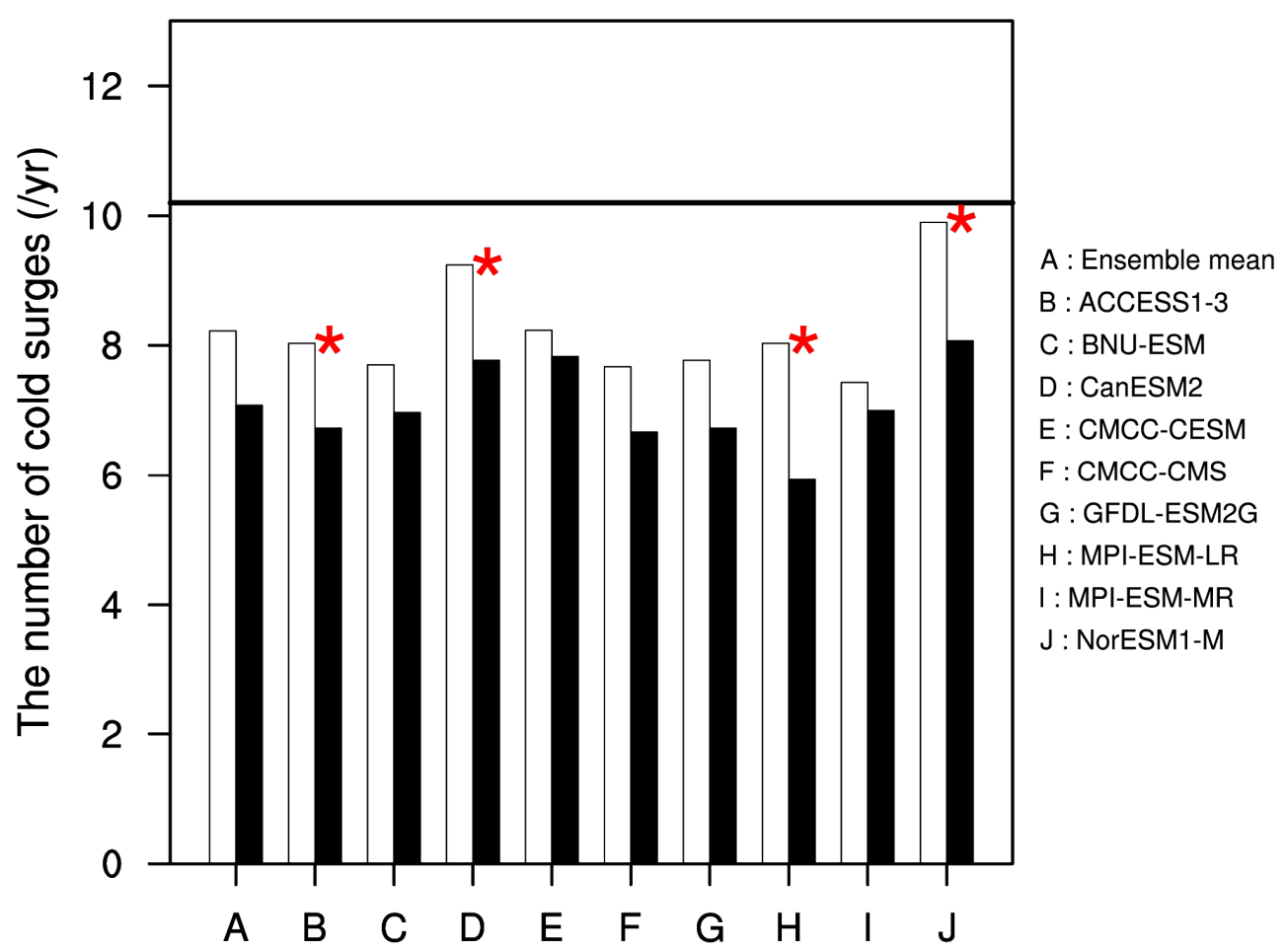

Figure 8. The number of cold surge occurrences $\left(\mathrm{yr}^{-1}\right)$ in winter from 1979-2016 in observations (horizontal black line) and the historical (1975-2005; white bar), and future (RCP8.5; 2065-2095; black bar) from 9 CGCMs and their ensemble means (significant changes at $95 \%$ confidence level are represented by red stars).

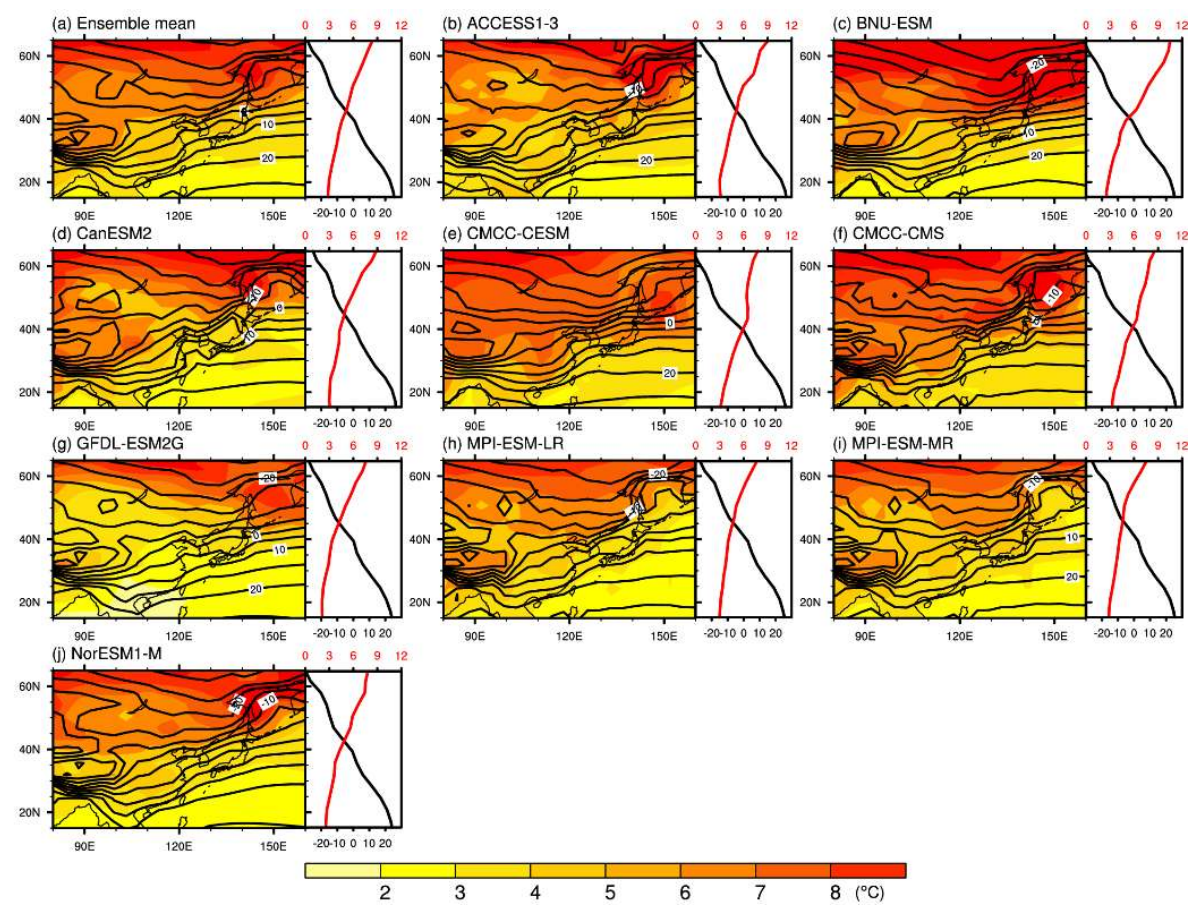

Figure 9. The SAT climatology for the historical run (1975-2005; shown as a contour with intervals of $5{ }^{\circ} \mathrm{C}$ ). Changes in SAT between 2065-2095 and 1975-2005 (shading; left) from nine CGCMs and their ensemble mean. The climatology of zonal mean SAT along $80^{\circ} \mathrm{E}$ to $160^{\circ} \mathrm{E}$ (black lines) and its change (red lines) in winter from nine CGCMs and their ensemble mean. 
In addition, circulation changes related to the EAWM and AO can affect SAT patterns in the lower troposphere. The EAWM is related to the circulation structure over East Asia, so we examined the projected changes in circulation patterns in the upper and lower troposphere in the future (Figure 10). The East Asian westerly jet stream is projected to shift poleward in the ensemble mean (Figure 10a). CMCC-CESM, CMCC-CMS, MPI-ESM-LR, and MPI-ESM-MR simulate particularly strong poleward shifts (Figure 10e,f,h,i). The enhancement of the jet stream on the northern flank of jet stream's core is a noticeable feature of weak EAWM years [38]. Projected changes in zonal wind at $250 \mathrm{hPa}$ are similar to the pattern in weak EAWM years. In the lower troposphere, zonal wind is projected to intensify over the regions where the East Asian westerly jet intensifies. On the other hand, zonal wind at $850 \mathrm{hPa}$ is projected to decrease over low-latitude regions. This anticyclonic change dominates over the western North Pacific around $40^{\circ} \mathrm{N}$ as the weak EAWM pattern does. Both the upper and lower level circulation changes imply a climatological weakening of the EAWM and a decrease in the number of CS occurrences in the future due to weakened cold advection.

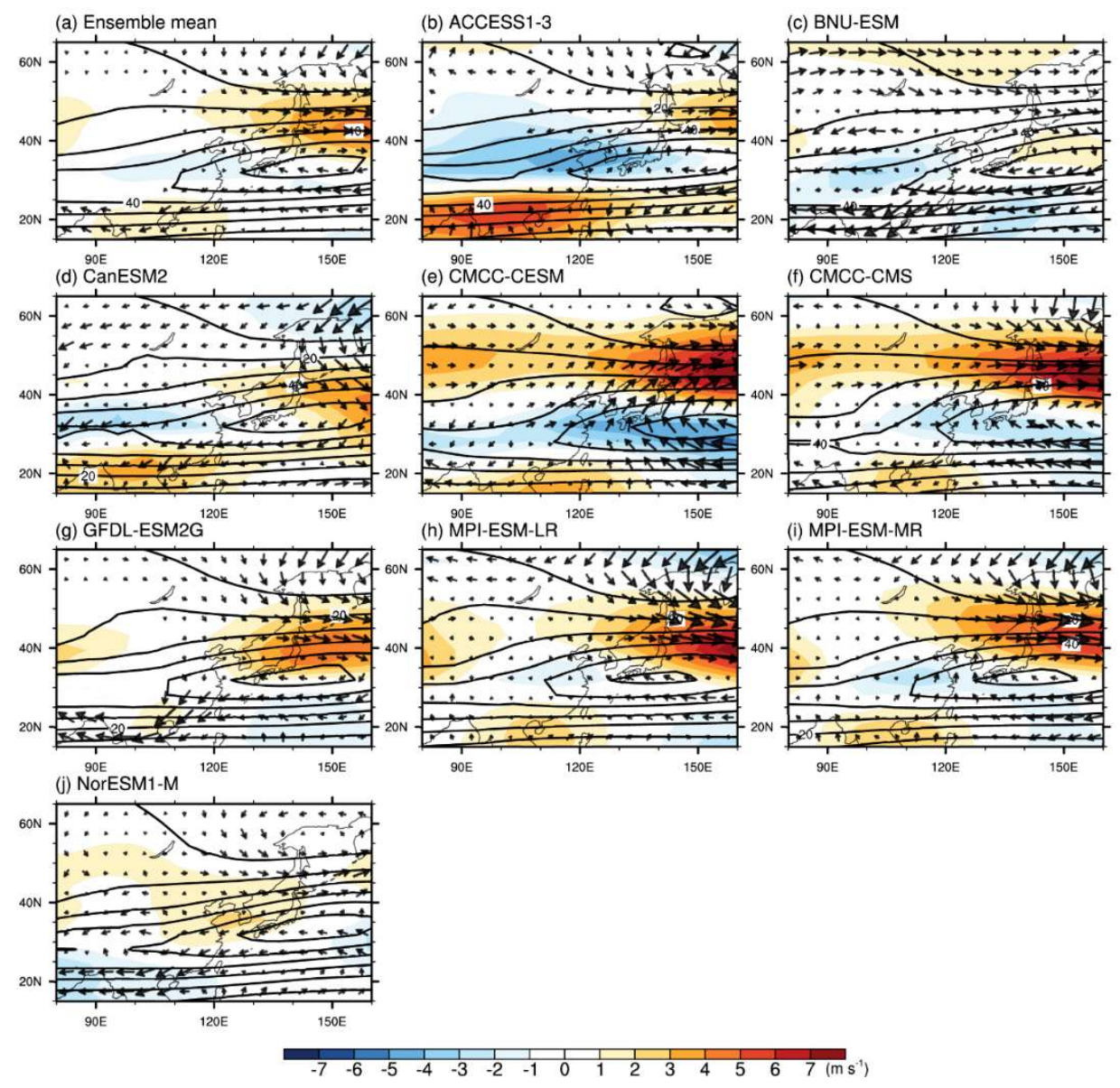

Figure 10. The climatology of zonal wind at $250 \mathrm{hPa}$ (contour: intervals of $10 \mathrm{~m} \mathrm{~s}^{-1}$ ) for 1975-2005 and the changes in zonal wind at $250 \mathrm{hPa}$ (shading) and wind vector at $850 \mathrm{hPa}\left(\mathrm{m} \mathrm{s}^{-1}\right)$ in winter from nine CGCMs and their ensemble mean.

The AO can also affect CS occurrences over East Asia by modulating atmospheric circulation $[13,14]$. All CGCMs successfully simulate the AO pattern, in which negative SLP anomalies are located over the Arctic Ocean and positive SLP anomalies are located over the North Pacific and North Atlantic, as determined by empirical orthogonal function analysis (not shown). Regression analysis of the historical run shows that the SAT gradient is reduced from Mongolia to East Asia in the positive AO phase (Figure 11). The projection value between the AO loading pattern and the mean SLP change in future climate is positive in all the CGCMs, with a value of +0.55 for the ensemble mean. 
The AO-related temperature change is expected to reduce the meridional SAT from Mongolia to East Asia, preventing the northerly from bringing cold air to develop CSs. Thus, the likely influence of the $\mathrm{AO}$ on East Asia in the future would be to provide unfavorable conditions for CS occurrences.
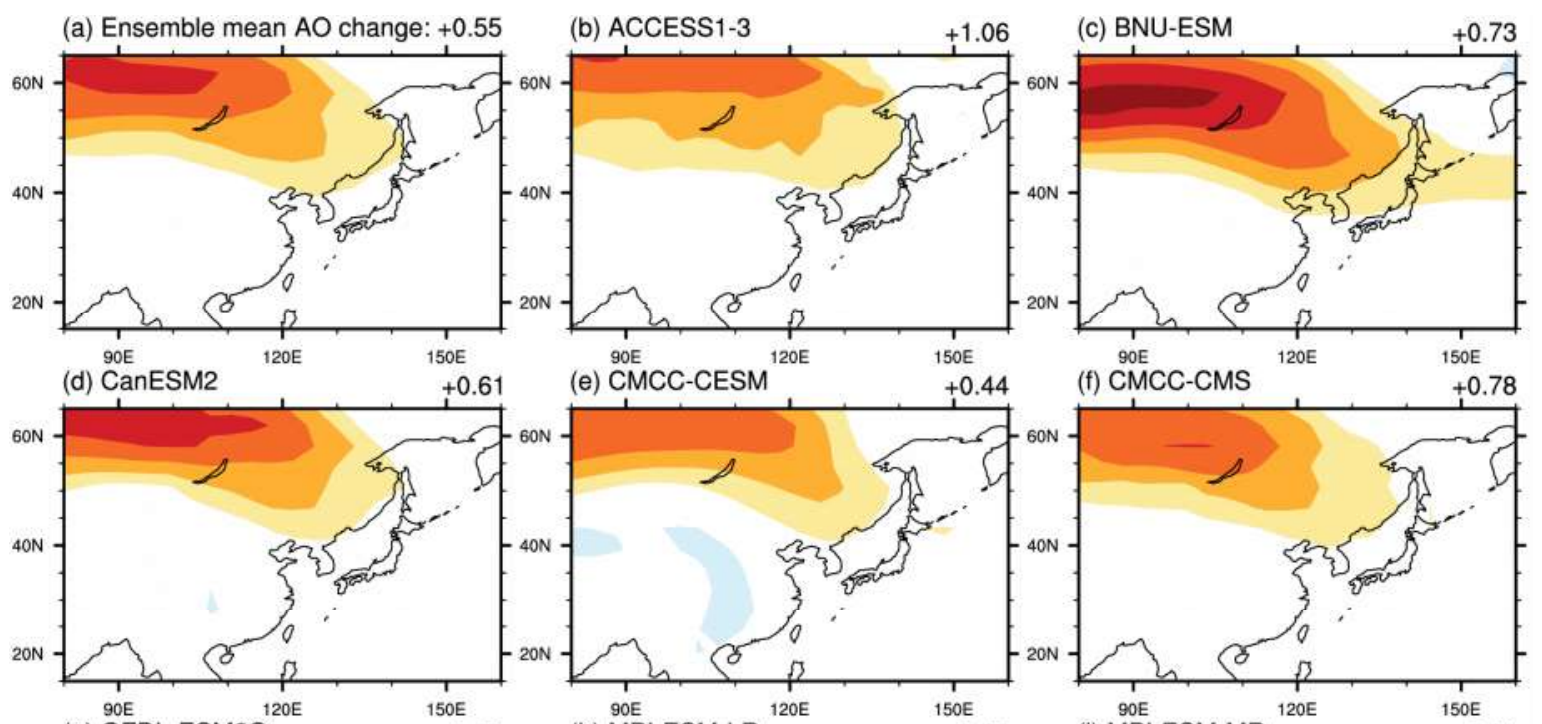

(e) CMCC-CESM
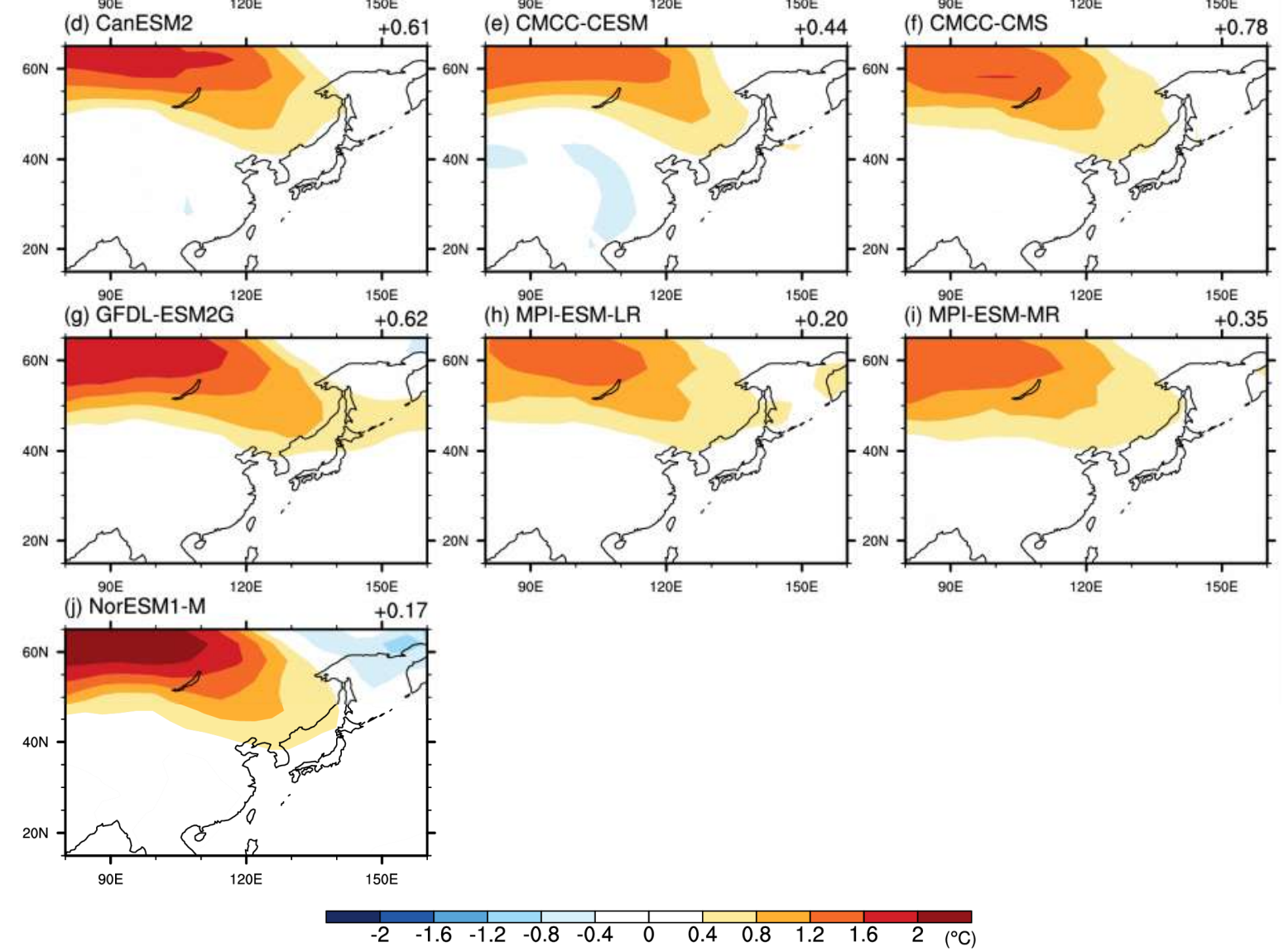

Figure 11. Regression coefficient maps for SAT anomalies based on the AO index for 1975-2005. The values in the top-right of each panel show the projection values between the AO pattern and changes in the mean SLP between 2065-2095 and 1975-2005 from nine CGCMs and their ensemble mean.

\section{Discussion and Summary}

In this study, changes in the occurrence of CSs in East Asia under climate warming are examined by analyzing observations and the CMIP5 simulations under the RCP8.5 scenario. All the chosen climate models investigated here predict reduced occurrence of CSs in the late 21st century. We suggest that changes in cold advection related to changes in the meridional SAT gradient are the primary contributors to future changes in the frequency of CS occurrences. As meridional SAT gradients are projected to decrease over East Asia in the late 21st century, the ability of the northerly winds to bring cold air to East Asia would be reduced compared to that in the present-day climate. Furthermore, 
projected changes in the large-scale atmospheric circulation, such as a more positive $\mathrm{AO}$ and a weaker EAWM, would contribute to the decrease in the frequency of CS occurrences.

Three limitations of the present study must be considered. First, we only used one ensemble member of each CGCM, which could lead to bias due to model-generated climatic internal variability. However, the relationship between CS occurrence and low-level thermodynamic structure should not be sensitive to the number of ensemble members because the nine CGCMs show consistent results. Second, our results are restricted by the limitation of the nine CGCMs. The most CGCMs project higher-latitude warming in future climates, so we expect our findings could be applicable to other CGCMs. Finally, Park et al. $[33,34]$ classify CSs into wave-train and blocking CSs, but we do not consider separate CS types. In wave-train CSs, the Siberian High intensifies by interaction with a baroclinic wave-train from Eurasia [9], while blocking CSs follow the retrogression of the blocking from the North Pacific [36]. Although our study does not distinguish between the two types, cold advection, which is the focus of the present study, is essential to the SAT drop in both types. Differences between the two CS types will be considered in a separate study.

We demonstrate that changes in cold advection play an important role in change of CS occurrences over East Asia. Over the past few decades, the Arctic has undergone more SAT warming than any other region of the globe, which has reduced SAT variability over high-latitude regions by weakening thermal advection in winter [30]. Although the number of CS occurrences has not shown a significant trend in recent decades, the relationship between CSs and SAT distributions holds on the interdecadal time scale. In the late 21st century, all of eastern Eurasia is expected to experience not only SAT warming but also a reduced meridional SAT gradient. This study shows that long-term temperature variations and differential warming patterns according to latitude strongly affect the climate of China and Korea. Future mid-latitude extreme weather studies, including studies of East Asian CSs, will benefit from improved climate models and establishment of more elaborate theories.

Supplementary Materials: The following are available online at http:/ /www.mdpi.com/2073-4433/9/6/222/s1. Figure S1: The climatology of mean sea level pressure (hPa) for 1979-2016 in observation and 1975-2005 in CGCMs during winter season, respectively. Table S1: The standard deviation of daily SAT anomaly and climatology of SAT over each SAT domain in observation and CMIP5 models.

Author Contributions: Conceptualization, J.-W.H., C.-H.H., T.-W.P. and W.C.; Formal analysis, J.-W.H.; Investigation, J.-W.H.; Methodology, J.-W.H., C.-H.H., T.-W.P. and W.C.; Supervision, C.-H.H.; Visualization, J.-W.H.; Writing—original draft, J.-W.H.; Writing—review \& editing, C.-H.H., T.-W.P., W.C., J.-H.J. and J.K.

Funding: This study was funded by the Korea Ministry of Environment (MOE) as part of the Climate Change Correspondence Program. Tae-Won Park was supported by the National Research Foundation of Korean government (Grant NRF-2015R1D1A1A01058100).

Conflicts of Interest: The authors declare no conflicts of interest.

\section{References}

1. Lu, F.C.; Henry Juang, H.M.; Liao, C.C. A numerical case study of the passage of a cold surge across Taiwan. Meteorol. Atmos. Phys. 2007, 95, 27-52. [CrossRef]

2. Chen, Y.; Ding, Y. Cold Air Activities in July 2004 and Its Impact on Intense Rainfalls over Southwest China. Acta Meteorol. Sin. 2007, 21, 302-319.

3. Chen, T.-C.; Yen, M.-C.; Huang, W.-R.; Gallus, W.A. An East Asian Cold Surge: Case Study. Mon. Weather Rev. 2002, 130, 2271-2290. [CrossRef]

4. Lu, Q.F.; Zhang, W.J.; Zhang, P.; Wu, X.B.; Zhang, F.Y.; Liu, Z.Q.; Dale, M.B. Monitoring the 2008 cold surge and frozen disasters snowstorm in South China based on regional ATOVS data assimilation. Sci. China Earth Sci. 2010, 53, 1216-1228. [CrossRef]

5. Yang, G.; Kong, Q.; Mao, D.; Zhang, F.; Kang, Z.; Zong, Z. Analysis on the long-lasting freezing rain and snowstorm event at the beginning of 2008. Acta Meteorol. Sin. 2009, 24, 380-396.

6. Zhang, Y.; Sperber, K.R.; Boyle, J.S. Climatology and Interannual Variation of the East Asian Winter Monsoon: Results from the 1979-1995 NCEP/NCAR Reanalysis. Mon. Weather Rev. 1997, 125, 2605-2619. [CrossRef] 
7. Ding, Y.; Krishnamurti, T.N. Heat Budget of the Siberian High and the Winter Monsoon. Mon. Weather Rev. 1987, 115, 2428-2449. [CrossRef]

8. Ding, Y. Build-up, air mass transformation and propagation of Siberian high and its relations to cold surge in East Asia. Meteorol. Atmos. Phys. 1990, 44, 281-292. [CrossRef]

9. Takaya, K.; Nakamura, H. Mechanisms of Intraseasonal Amplification of the Cold Siberian High. J. Atmos. Sci. 2005, 62, 4423-4440. [CrossRef]

10. Park, T.-W.; Jeong, J.-H.; Ho, C.-H.; Kim, S.-J. Characteristics of Atmospheric Circulation Associated with Cold Surge Occurrences in East Asia: A Case Study During 2005/06 Winter. Adv. Atmos. Sci. 2008, 25, 791-804. [CrossRef]

11. Thompson, D.W.J.; Wallace, J.M. The Arctic oscillation signature in the wintertime geopotential height and temperature fields. Geophys. Res. Lett. 1998, 25, 1297-1300. [CrossRef]

12. Madden, R.A.; Julian, P.R. Detection of a 40-50 Day Oscillation in the Zonal Wind in the Tropical Pacific. J. Atmos. Sci. 1971, 28, 702-708. [CrossRef]

13. Jeong, J.H.; Ho, C.H. Changes in occurrence of cold surges over east Asia in association with Arctic Oscillation. Geophys. Res. Lett. 2005, 32, L14704. [CrossRef]

14. Park, T.W.; Ho, C.H.; Yang, S. Relationship between the arctic oscillation and cold surges over East Asia. J. Clim. 2011, 24, 68-83. [CrossRef]

15. Woo, S.H.; Kim, B.M.; Jeong, J.H.; Kim, S.J.; Lim, G.H. Decadal changes in surface air temperature variability and cold surge characteristics over northeast Asia and their relation with the Arctic Oscillation for the past three decades (1979-2011). J. Geophys. Res. Atmos. 2012, 117, 1-16. [CrossRef]

16. Jeong, J.H.; Ho, C.H.; Kim, B.M.; Kwon, W.T. Influence of the Madden-Julian Oscillation on wintertime surface air temperature and cold surges in east Asia. J. Geophys. Res. D Atmos. 2005, 110, 1-7. [CrossRef]

17. Wang, B.; Wu, Z.; Chang, C.P.; Liu, J.; Li, J.; Zhou, T. Another look at interannual-to-interdecadal variations of the east Asian winter monsoon: The northern and southern temperature modes. J. Clim. 2010, 23, 1495-1512. [CrossRef]

18. Overland, J.E.; Dethloff, K.; Francis, J.A.; Hall, R.J.; Hanna, E.; Kim, S.-J.; Screen, J.A.; Shepherd, T.G.; Vihma, T. Nonlinear response of mid-latitude weather to the changing Arctic. Nat. Publ. Gr. 2016, 6, 992-999. [CrossRef]

19. Honda, M.; Inoue, J.; Yamane, S. Influence of low Arctic sea-ice minima on anomalously cold Eurasian winters. Geophys. Res. Lett. 2009, 36, 1-6. [CrossRef]

20. Mori, M.; Watanabe, M.; Shiogama, H.; Inoue, J.; Kimoto, M. Robust Arctic sea-ice influence on the frequent Eurasian cold winters in past decades. Nat. Geosci. 2014, 7, 869-873. [CrossRef]

21. Kim, B.M.; Son, S.W.; Min, S.K.; Jeong, J.H.; Kim, S.J.; Zhang, X.; Shim, T.; Yoon, J.H. Weakening of the stratospheric polar vortex by Arctic sea-ice loss. Nat. Commun. 2014, 5, 1-8. [CrossRef] [PubMed]

22. Alexander, L.V.; Zhang, X.; Peterson, T.C.; Caesar, J.; Gleason, B.; Klein Tank, A.M.G.; Haylock, M.; Collins, D.; Trewin, B.; Rahimzadeh, F.; et al. Global observed changes in daily climate extremes of temperature and precipitation. J. Geophys. Res. Atmos. 2006, 111, 1-22. [CrossRef]

23. Park, T.W.; Ho, C.H.; Jeong, S.J.; Choi, Y.S.; Park, S.K.; Song, C.K. Different characteristics of cold day and cold surge frequency over East Asia in a global warming situation. J. Geophys. Res. Atmos. 2011, 116, 1-12. [CrossRef]

24. Choi, Y.; Ho, C.; Gong, D.; Jeong, J.; Park, T. Adaptive Change in Intra-Winter Distribution of Relatively Cold Events to East Asian Warming. Terr. Atmos. Ocean. Sci. 2009, 20, 807-816. [CrossRef]

25. Francis, J.A.; Vavrus, S.J. Evidence linking Arctic amplification to extreme weather in mid-latitudes. Geophys. Res. Lett. 2012, 39, 4734-4739. [CrossRef]

26. Cohen, J.; Screen, J.A.; Furtado, J.C.; Barlow, M.; Whittleston, D.; Coumou, D.; Francis, J.; Dethloff, K.; Entekhabi, D.; Overland, J.; et al. Recent Arctic amplification and extreme mid-latitude weather. Nat. Geosci. 2014, 7, 627-637. [CrossRef]

27. Screen, J.A.; Deser, C.; Sun, L. Projected changes in regional climate extremes arising from Arctic sea ice loss. Environ. Res. Lett. 2015, 10. [CrossRef]

28. Kug, J.-S.; Jeong, J.-H.; Jang, Y.-S.; Kim, B.-M.; Folland, C.K.; Min, S.-K.; Son, S.-W. Two distinct influences of Arctic warming on cold winters over North America and East Asia. Nat. Geosci. 2015, 8, 759-762. [CrossRef]

29. Barnes, E.A.; Screen, J.A. The impact of Arctic warming on the midlatitude jet-stream: Can it? Has it? Will it? Wiley Interdiscip. Rev. Clim. Chang. 2015, 6, 277-286. [CrossRef] 
30. Screen, J.A. Arctic amplification decreases temperature variance in northern mid- to high-latitudes. Nat. Clim. Chang. 2014, 4, 577-582. [CrossRef]

31. Dee, D.P.; Uppala, S.M.; Simmons, A.J.; Berrisford, P.; Poli, P.; Kobayashi, S.; Andrae, U.; Balmaseda, M.A.; Balsamo, G.; Bauer, P.; et al. The ERA-Interim reanalysis: Configuration and performance of the data assimilation system. Q. J. R. Meteorol. Soc. 2011, 137, 553-597. [CrossRef]

32. Taylor, K.E.; Stouffer, R.J.; Meehl, G.A. An overview of CMIP5 and the experiment design. Bull. Am. Meteorol. Soc. 2012, 93, 485-498. [CrossRef]

33. Park, T.W.; Ho, C.H.; Deng, Y. A synoptic and dynamical characterization of wave-train and blocking cold surge over East Asia. Clim. Dyn. 2014, 43, 753-770. [CrossRef]

34. Park, T.W.; Ho, C.H.; Jeong, J.H.; Heo, J.W.; Deng, Y. A new dynamical index for classification of cold surge types over East Asia. Clim. Dyn. 2015, 45, 2469-2484. [CrossRef]

35. Park, T.W.; Heo, J.W.; Jeong, J.H.; Ho, C.H. Characteristics of East Asian Cold Surges in the CMIP5 Climate Models. Atmosphere 2017, 27, 199-211. [CrossRef]

36. Takaya, K.; Nakamura, H. Geographical dependence of upper-level blocking formation associated with intraseasonal amplification of the Siberian high. J. Atmos. Sci. 2005, 4441-4449. [CrossRef]

37. Ou, T.; Chen, D.; Jeong, J.H.; Linderholm, H.W.; Zhou, T. Changes in winter cold surges over Southeast China: 1961 to 2012. Asia-Pac. J. Atmos. Sci. 2015, 51, 29-37. [CrossRef]

38. Jhun, J.G.; Lee, E.J. A new East Asian winter monsoon index and associated characteristics of the winter monsoon. J. Clim. 2004, 17, 711-726. [CrossRef]

(C) 2018 by the authors. Licensee MDPI, Basel, Switzerland. This article is an open access article distributed under the terms and conditions of the Creative Commons Attribution (CC BY) license (http://creativecommons.org/licenses/by/4.0/). 